\title{
Exigência de proteína bruta para juvenis de pacamã
}

\author{
Crude protein requeriment to pacamã juveniles
}

\author{
SOUZA, Márcia Gomes de ${ }^{1}$; SEABRA, Ana Gabriela Lins ${ }^{1}$; SILVA, Lilian Carolina \\ Rosa $\mathrm{da}^{2}$; SANTOS, Lilian Dena dos²; BALEN, Rafael Ernesto ${ }^{3 *}$; MEURER, Fábio ${ }^{2}$
}

\author{
${ }^{1}$ Universidade Federal do Vale do São Francisco, Programa de Pós-Graduação em Ciência Animal, \\ Petrolina, Pernambuco, Brasil \\ ${ }^{2}$ Universidade Federal do Paraná, Programa de Pós-Graduação em Aquicultura e Desenvolvimento \\ Sustentável, Palotina, Paraná, Brasil \\ ${ }^{3}$ Universidade Federal do Paraná, Programa de Pós-Graduação em Zoologia, Curitiba, Paraná, Brasil \\ *Endereço para correspondência: rebalen@yahoo.com.br
}

\section{RESUMO}

O pacamã (Lophiosilurus alexandri) é uma espécie de peixe com hábito alimentar carnívoro, apropriada para o cultivo, porém, ainda pouco estudada. O objetivo deste estudo foi determinar a exigência de proteína bruta (PB) do pacamã, L. alexandri, na fase juvenil. O experimento foi conduzido por um período de 45 dias utilizando um delineamento inteiramente casualizado, com cinco tratamentos (dieta contendo 36,$2 ; 38,2 ; 42,0 ; 44,4$ e $48,8 \%$ de PB) e quatro repetições cada, onde 100 juvenis $(5,19 \pm 0,01 \mathrm{~g})$ foram distribuídos em 20 caixas com volume útil de $36 \mathrm{~L}$, sendo considerada como unidade experimental uma caixa com cinco juvenis. Foram avaliados os parâmetros de peso final, percentagem de ganho de peso, taxa de crescimento específico, sobrevivência, índice hepatossomático, rendimento de carcaça com e sem cabeça, comprimento total, comprimento da cabeça, largura e altura. Pela análise de regressão foi verificada uma redução linear $(\mathrm{P}<0.01)$ nos parâmetros de desempenho em função do nível protéico da ração. Quando comparados pelo teste de Tukey, o melhor resultado $(\mathrm{P}<0.01)$ foi obtido com $36,2 \%$ de PB. Não houve influência dos tratamentos nos outros parâmetros avaliados $(\mathrm{p}>0,05)$. Deste modo, recomenda-se a utilização de rações contendo entre $36,2 \%$ de proteína bruta para juvenis de pacamã ( $L$. alexandri).

Palavras-chave: Lophiosilurus alexandri, nutrição de peixes, peixe carnívoro, peixe nativo

\section{SUMMARY}

Pacamã (Lophiosilurus alexandri) is a species of carnivorous fish, suitable for farming, but little studied. The aim of this study was to determinate crude protein $(\mathrm{CP})$ requirement to pacamã, L. alexandri, in juvenile phase, an experiment was conducted during 45 days in a completely randomized design, with five treatments $(36.2,38.2,42.0,44.4$, and $48.8 \%$ $\mathrm{CP}$ of diet) and four replications, where a hundred juvenile fishes $(5.19 \pm 0.01 \mathrm{~g})$ were distributed in twenty $36 \mathrm{~L}$ aquaria. Each aquarium with five juveniles was considered an experimental unit. The parameters evaluated were final weight, percentage weight gain, specific growth rate, survival rate, hepatosomatic index, carcass yield with and without head, total length, head length, width, and height. By the regression analysis was verify a $(\mathrm{P}<0.01)$ linear decrease to performance parameters in function to ration protein growth, however to Tukey test the best $(\mathrm{P}<0.01)$ result was obtained with $36.2 \%$ of CP. There was no influence of treatments on the other evaluated parameters $(p>0.05)$. Thus, it is recommended to use feed containing $36.2 \%$ of crude protein to pacamã (L. alexandri) juveniles.

Keywords: carnivorous fish, fish nutrition, Lophiosilurus alexandri, native fish 


\section{INTRODUÇÃO}

O Rio São Francisco possui diversas espécies de peixes com potencial para cultivo e o estudo das mesmas pode proporcionar sua inserção no panorama atual do cultivo racional e auxiliar na manutenção de espécies nativas que, muitas vezes, dependem de estações de piscicultura para trabalhos de repovoamento (MEURER et al., 2010).

O pacamã (Lophiosilurus alexandri) é um peixe de hábito alimentar carnívoro, endêmico da bacia do rio São Francisco (TENÓRIO et al., 2006), que tem despertado o interesse de pesquisadores e produtores em virtude de ser bastante apreciado pela população local, ter carne muito saborosa e alto valor comercial (LUZ \& SANTOS, 2008).

$\mathrm{O}$ desequilíbrio ambiental ocasionado pela introdução de espécies exóticas requer maior tecnificação da criação de espécies nativas e, desta forma, maior demanda de pesquisas nesta área (HAYASHI et al., 2004). Soares et al. (2007) citam que o grande entrave na produção de peixes carnívoros ainda se encontra na nutrição, que, por sua vez, ainda não está bem definida para várias espécies. $O$ suprimento dietético de proteína é um dos principais fatores que influenciam a produtividade dos peixes, a composição corporal e a produção de resíduos nitrogenados que são excretados na água (TIBBETS et al., 2000; FERNANDES et al., 2001; SÁ \& FRACALOSSI, 2002; MEURER et al., 2007).

Desta forma, a determinação dos valores de exigência protéica é fundamental para o cultivo racional da espécie, bem como tem sido o elemento inicial para o desenvolvimento da pesquisa, principalmente em se tratando de espécies com pouco estudo e grande potencial aquícola, como é o caso do pacamã (CARDOSO et al., 1996; BARROS et al., 2007; GODINHO, 2007).

Conduziu-se este trabalho com o objetivo de avaliar os efeitos de diferentes níveis dietéticos de proteína bruta sobre o desempenho de juvenis de pacamã (L. alexandri).

\section{MATERIAL E MÉTODOS}

O estudo foi conduzido no Laboratório de Aquicultura localizado no Campus de Ciências Agrárias, Universidade Federal do Vale do São Francisco, em Petrolina - PE, durante um período de 45 dias. Foram utilizados 100 juvenis de pacamã, doados pela Companhia de Desenvolvimento dos Vales do São Francisco e do Parnaíba (CODEVASF), com peso inicial de 5,19 $\pm 0,01 \mathrm{~g}$, distribuídos em um delineamento experimental inteiramente casualizado, com cinco tratamentos e quatro repetições em 20 caixas plásticas de $36 \mathrm{~L}$ de volume útil. Cada caixa contendo cinco juvenis foi considerada como unidade experimental.

Os tratamentos foram constituídos por rações com níveis crescentes de proteína bruta (Tabela 1). A fabricação e processamento da ração foi feito de acordo com os dados disponibilizados por SEABRA (2010). Os peletes foram moídos e separados por meio de peneiras com malhas de diferentes tamanhos, para adequação dos mesmos ao tamanho da boca dos juvenis. As rações foram acondicionadas em frascos de polietileno e armazenadas sob refrigeração.

$\mathrm{O}$ arraçoamento foi feito duas vezes ao dia ( $8 \mathrm{~h}$ e $18 \mathrm{~h})$, "ad libitum". As rações foram analisadas no Laboratório de Nutrição Animal do Curso de Zootecnia do Campus de Ciências Agrárias da 
Rev. Bras. Saúde Prod. Anim., Salvador, v.14, n.2, p.362-370 abr./jun., 2013 http://www.rbspa.ufba.br ISSN 15199940

Universidade Federal do Vale do São Francisco, Petrolina - PE, quanto aos valores de proteína bruta, matéria seca, extrato etéreo, energia bruta e cinzas, conforme procedimentos descritos por SILVA \& QUEIROZ (2006).

Tabela 1. Composição percentual e bromatológica das rações experimentais contendo níveis crescentes de proteína bruta fornecida aos juvenis de pacamã $(L$. alexandri)

\begin{tabular}{|c|c|c|c|c|c|}
\hline \multirow{2}{*}{ Ingredientes (\%) } & \multicolumn{5}{|c|}{ Percentagem de proteína bruta da ração } \\
\hline & 36,2 & 38,2 & 42,0 & 45,4 & 48,8 \\
\hline Farinha de vísceras de aves & 35,65 & 40,73 & 45,81 & 36,61 & 25,74 \\
\hline Farinha peixe & 20,00 & 20,00 & 20,00 & 20,00 & 20,00 \\
\hline Inerte $^{1}$ & 19,32 & 17,33 & 15,35 & 10,00 & 5,62 \\
\hline Óleo de soja & 6,52 & 3,43 & 0,32 & 0,00 & 0,00 \\
\hline Farinha de carne e ossos & 5,00 & 5,00 & 5,00 & 19,22 & 35,12 \\
\hline Farelo de soja & 5,00 & 5,00 & 5,00 & 5,00 & 5,00 \\
\hline Milho & 5,00 & 5,00 & 5,00 & 5,00 & 5,00 \\
\hline Pré-mistura vit.-mineral ${ }^{2}$ & 3,00 & 3,00 & 3,00 & 3,00 & 3,00 \\
\hline Sal comum & 0,50 & 0,50 & 0,50 & 0,50 & 0,50 \\
\hline $\mathrm{BHT}^{3}$ & 0,01 & 0,01 & 0,01 & 0,01 & 0,01 \\
\hline Total & 100,00 & 100,00 & 100,00 & 100,00 & 100,00 \\
\hline Nutriente $(\%)$ & \multicolumn{5}{|c|}{ Composição bromatológica } \\
\hline Matéria seca & 95,68 & 94,42 & 96,44 & 97,71 & 98,00 \\
\hline Cinzas & 6,6 & 6,9 & 7,0 & 6,7 & 6,8 \\
\hline Energia bruta (kcal/g) & $3.293,6$ & $3.279,4$ & $3.112,3$ & $3.373,2$ & $3.430,4$ \\
\hline Extrato etéreo & 16,90 & 16,10 & 16,14 & 14,16 & 14,10 \\
\hline
\end{tabular}

Areia; ${ }^{2}$ Supremais; ${ }^{3}$ Butil-hidroxi-tolueno.

As caixas experimentais fizeram parte de um sistema de recirculação de água acoplada a um biofiltro (1.000L). A oxigenação da água foi realizada através de um soprador de ar ligado por meio de mangueiras plásticas a pedras microporosas, uma por caixa. A temperatura da água foi mantida em $26^{\circ} \mathrm{C}$ utilizando-se dois aquecedores de $300 \mathrm{~W}$ ligados na caixa do biofiltro.

As variáveis físico-químicas da água das unidades experimentais, condutividade e oxigênio dissolvido foram aferidos uma vez por semana, enquanto que $\mathrm{pH}$ e temperatura duas vezes ao dia $(7 \mathrm{~h} \mathrm{e}$ 17h). Após a obtenção das medidas de qualidade de água, e antes do arraçoamento, as caixas foram sifonadas para retirada de fezes e possíveis restos de ração, sendo a água reposta.

Ao final do período experimental, os peixes de cada unidade foram pesados e medidos para obtenção das variáveis de peso final, percentagem de ganho de peso, taxa de crescimento específico, sobrevivência, comprimento total, comprimento da cabeça, largura e altura. Após insensibilização por imersão em água fria $\left( \pm 2^{\circ} \mathrm{C}\right)$, foram retiradas as vísceras de todos os animais, separados os 
fígados e, então, pesados, para o cálculo do índice hepatossomático e do rendimento de carcaça com e sem cabeça.

Os parâmetros de desempenho, biométricos e de sobrevivência foram submetidos à análise de variância, sendo as médias contrastantes comparadas pelo teste de Tukey, a 5\% de probabilidade, e de regressão utilizando-se o software SAEG Sistema de Análises Estatísticas e Genéticas (UFV, 1997).

\section{RESULTADOS E DISCUSSÃO}

As médias dos parâmetros de qualidade da água monitorados durante $\mathrm{o}$ experimento permaneceram dentro dos valores adequados à piscicultura, com temperatura de $26,05 \pm 2,4^{\circ} \mathrm{C}$; oxigênio dissolvido $5,8 \pm 1,3 \mathrm{mg} / \mathrm{L} ; \mathrm{pH}$ 7,69 $\pm 0,4$ e condutividade elétrica $52,4 \quad \pm$ $2,7 \mu \mathrm{S} / \mathrm{cm}$.

Os valores médios dos parâmetros de desempenho e sobrevivência estão contidos na Tabela 2 , enquanto que o efeito dos diferentes níveis de proteína bruta sobre o peso final, ganho de peso, taxa de crescimento específico e comprimento total dos juvenis de pacamã está apresentado na Figura 1 .

O peso inicial dos juvenis de pacamã submetidos às rações com níveis crescentes de proteína bruta $(\mathrm{PB})$ não apresentou diferença entre os tratamentos $(\mathrm{P}>0,05)$, demonstrando a homogeneidade dos lotes que iniciaram o experimento. Os valores médios de sobrevivência, índice hepatossomático, comprimento de cabeça, largura, altura, rendimento de carcaça com cabeça e rendimento de carcaça sem cabeça também não foram influenciados pelo nível de proteína bruta na ração $(\mathrm{P}>0,05)$.

Tabela 2. Parâmetros avaliados dos juvenis de pacamã (Lophiosilurus alexandri) alimentados com níveis crescentes de proteína bruta*

\begin{tabular}{|c|c|c|c|c|c|c|}
\hline \multirow{2}{*}{ Item } & \multicolumn{5}{|c|}{ Nível de proteína bruta (\%) da ração } & \multirow{2}{*}{$\begin{array}{l}\mathrm{CV} \\
(\%)\end{array}$} \\
\hline & 36,2 & 38,2 & 42,0 & 45,4 & 48,8 & \\
\hline Peso inicial $(g)$ & 5,19 & 5,19 & 5,19 & 5,19 & 5,19 & 0,16 \\
\hline Peso final médio (g) & $10,52^{\mathrm{ab}}$ & $11,23^{\mathrm{a}}$ & $7,56^{\mathrm{bc}}$ & $7,29^{\mathrm{c}}$ & $6,69^{\mathrm{c}}$ & 21,32 \\
\hline Ganho de peso (\%) & $533,42^{\mathrm{ab}}$ & $603,90^{\mathrm{a}}$ & $236,18^{\mathrm{bc}}$ & $209,70^{\mathrm{c}}$ & $150,87^{\mathrm{c}}$ & 34,12 \\
\hline Taxa de crescimento específico (\%) & $1,56^{\mathrm{ab}}$ & $1,70^{\mathrm{a}}$ & $0,83^{\mathrm{bc}}$ & $0,72^{\mathrm{c}}$ & $0,53^{\mathrm{c}}$ & 32,13 \\
\hline Índice hepatossomático (\%) & 1,76 & 1,92 & 1,98 & 1,53 & 1,29 & 28,09 \\
\hline Sobrevivência (\%) & 93,33 & 100,00 & 93,33 & 100,00 & 100,00 & 7,14 \\
\hline Comprimento total $(\mathrm{cm})$ & $9,33^{\mathrm{ab}}$ & $9,71^{\mathrm{a}}$ & $8,84^{\mathrm{ab}}$ & $8,46^{\mathrm{b}}$ & $8,59^{\mathrm{b}}$ & 5,06 \\
\hline Comprimento da cabeça $(\mathrm{cm})$ & 2,51 & 2,65 & 2,43 & 2,26 & 2,34 & 12,02 \\
\hline Largura $(\mathrm{cm})$ & 2,13 & 2,18 & 1,92 & 1,90 & 1,89 & 8,54 \\
\hline Altura (cm) & 0,79 & 0,79 & 0,77 & 0,69 & 0,69 & 25,35 \\
\hline Rendimento de carcaça com cabeça (\%) & 82,63 & 88,06 & 90,92 & 89,13 & 89,08 & 9,92 \\
\hline Rendimento de carcaça sem cabeça (\%) & 50,66 & 54,22 & 53,87 & 50,24 & 50,56 & 12,77 \\
\hline
\end{tabular}

*Números na mesma linha acompanhados de letras diferentes diferem pelo teste de Tukey $(\mathrm{P}<0,01)$. 
A

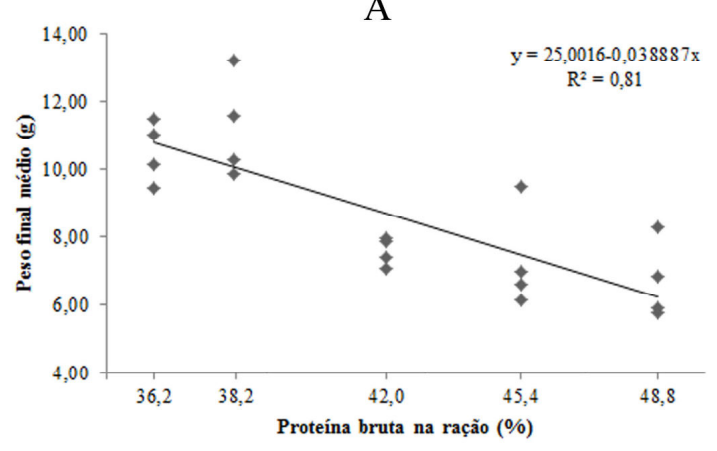

$\mathrm{C}$

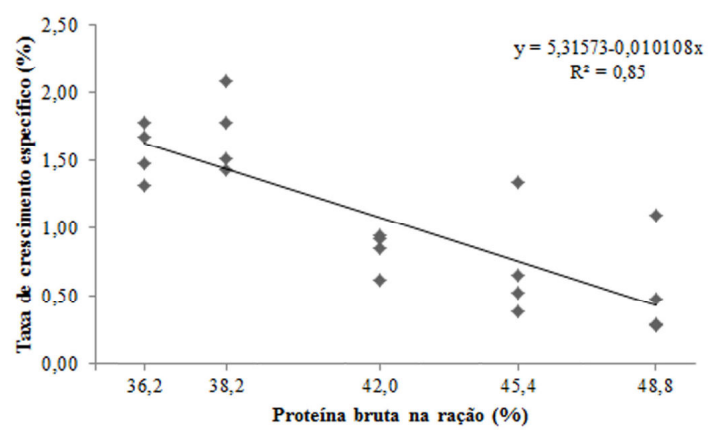

B

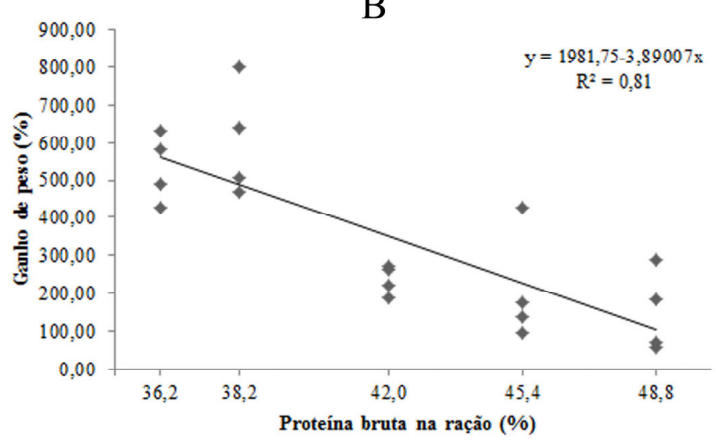

D)

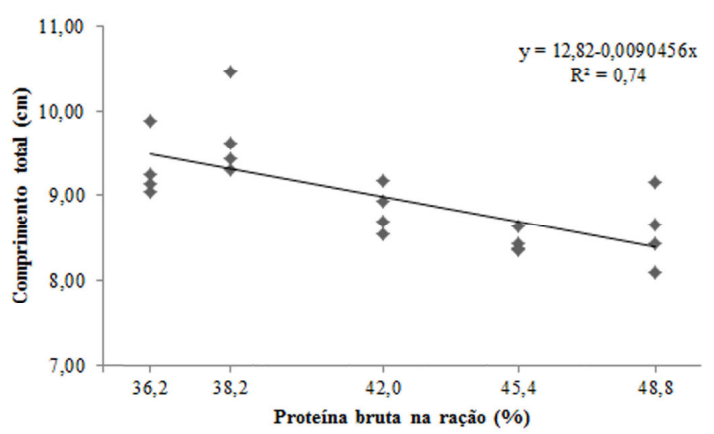

Figura 1. Peso final médio (A), ganho de peso (B), taxa de crescimento específico (C) e comprimento total (D) dos juvenis de pacamã (Lophiosilurus alexandri) alimentados com níveis crescentes de proteína bruta

Os parâmetros de peso final, percentagem de ganho de peso e taxa de crescimento específico reduziu linearmente $(\mathrm{P}<0,01)$ em função do aumento do nível de proteína bruta na ração. Quando analisados pelo teste de Tukey, o melhor resultado para estes parâmetros foi alcançado pelos juvenis de pacamã alimentados com a ração contendo $36,2 \%$ de $\mathrm{PB}$, enquanto o pior foi proporcionado pelas rações contendo 45,4 e 48,8\% PB, com os demais tratamentos mostrando-se intermediários.

Comportamento semelhante foi observado para o comprimento total.

Os juvenis de pacamã apresentam uma exigência protéica dietética inferior ao observado em outras espécies carnívoras, como relatado para alevinos de trairão (Hoplias lacerdae), que foi de $47,0 \%$ de PB (VERAS et al., 2010), alevinos de dourado (Salminus brasiliensis), de 45,4\% de PB (TEIXEIRA et al., 2010); e para juvenis de pirarucu (Arapaima gigas), de 48,6\% de PB (ITUASSÚ et al., 2005). Contudo, foi superior aos $32 \%$ de PB observados para juvenis de apaiari (Astronatus ocellatus) (FABREGAT et al., 2006) e assemelhou-se aos valores para alevinos de tucunaré (Cichla sp.), entre 37,0 e $41,0 \%$ PB (SAMPAIO et al., 2000).

Comparado com espécies onívoras e iliófagas, o valor de exigência de proteína bruta encontrado para os juvenis de pacamã foi superior aos determinados para alevinos de pacu (Piaractus mesopotamicus), 27,0\% de PB (BICUDO et al., 2010); juvenis de tambaqui (Colossoma macropomum), $30,0 \%$ de PB (OISHI et al., 2010), de pirapitinga (Piaractus brachypomus), $31,6 \%$ de PB (VÁSQUEZ-TORRES et 
al., 2011), de matrinxã (Brycon cephalus) na fase de crescimento, $28,0 \%$ de PB (IZEL et al., 2004) e curimbatá (Prochilodus affins), de $26,0 \%$ (BOMFIM et al., 2005). Entretanto, foi inferior ao de juvenis de jundiá (Rhamdia quelen), de $41,0 \%$ de PB (MELO et al., 2012).

Os valores de rendimento de carcaça com e sem cabeça foram semelhantes aos apresentados por MEURER et al. (2010) e SEABRA (2010) para alevinos da mesma espécie. Um ponto que merece destaque para o pacamã é o bom crescimento apresentado com a utilização de ração como fonte exclusiva de alimento na fase juvenil, corroborando SEABRA (2010), para alevinos alimentados com rações contendo $57,28 \%$ de PB, e contrariando o observado por PEDREIRA et al. (2008), para a fase de pós-larva.

A diferença entre o valor da exigência de PB para o pacamã, determinado no presente trabalho, com relação a outras espécies está provavelmente relacionada a diferenças entre aspectos da fisiologia, bem como hábito alimentar e fase de crescimento. Destaca-se a proximidade dos valores de exigência de espécies como o tucunaré e o jundiá, a primeira carnívora e a segunda onívora, esta, porém, segundo Gomes et al. (2000), com preferência por peixes, crustáceos e insetos.

Em relação aos resultados dos parâmetros de desempenho, nota-se claramente que a partir dos valores entre 36,2 e $38,2 \%$ de PB ocorre um decréscimo no crescimento do peixe, o mesmo foi verificado para o dourado (TEIXEIRA et al., 2010), para a pirapitinga (VÁSQUEZ-TORRES et al., 2011) e para o tambaqui (VIDAL JÚNIOR et al., 1998). Isto deve estar relacionado com a possível utilização de aminoácidos para a produção de energia (KAUSHIK \& SEILLEZ, 2010), já que, à medida que a quantidade de $\mathrm{PB}$ aumenta nas rações, a relação entre proteína (aminoácidos) e outras fontes de energia (lipídeos e/ou carboidratos) aumenta. Apesar da utilização de aminoácidos como fonte energética em peixes de água doce geralmente não acarretar em gasto energético, devido ao nitrogênio amoniacal ser excretado sem gasto, ocorre diminuição do aporte destes para a biossíntese de proteínas, decrescendo, consequentemente, o ganho de peso.

Considerando-se os parâmetros de desempenho avaliados, recomenda-se a utilização de rações contendo entre 36,2 de proteína bruta para juvenis de pacamã (L. alexandri).

\section{AGRADECIMENTOS}

Os autores agradecem a Fundação de Amparo à Ciência e Tecnologia do Estado de Pernambuco (FACEPE), o Conselho Nacional de Desenvolvimento Científico e Tecnológico (CNPq), a CODEVASF - Bebedouro, por ceder os animais utilizados na pesquisa, e a professora Adriana Yano-Melo pelo apoio incondicional no desenvolvimento deste trabalho.

\section{REFERÊNCIAS}

BARROS, M.D.M.; GUIMARÃESCRUZ, R.J.; VELOSO JÚNIOR, V.C.; SANTOS, J.E. Reproductive apparatus and gametogenesis of Lophiosilurus alexandri Steindachner (Pisces, Teleostei, Siluriformes). Revista

Brasileira de Zoologia, v.24, n.1, p.213-221, 2007.

BICUDO, A.J.A.; SADO, R.Y.; CYRINO, J.E.P. Growth performance and body composition of pacu Piaractus 
mesopotamicus (Holmberg 1887) in response to dietary protein and energy levels. Aquaculture Nutrition, v.16, n.2, p.213-222, 2010.

BOMFIM, M.A.D.; LANNA, E.A.T.; SERAFINI, M.A.; RIBEIRO, F.B.; PENA, K.S. Proteína bruta e energia digestível em dietas para alevinos de curimbatá (Prochilodus affins). Revista Brasileira de Zootecnia, v.34, n.6, p.1795-1806, 2005.

CARDOSO, E.L.; CHIARINI-GARCIA, H.; FERREIRA, R.M.A.; POLI, C.R. Morphological changes in the gills of Lophiosilurus alexandri exposed to unionized ammonia. Journal of Fish Biology, v.49, n.5, p.778-787, 1996.

FABREGAT, T.E.H.P.; FERNANDES, J.B.K.; RODRIGUES, L.A.; RIBEIRO, F.A.; SAKOMURA, N.K. Fontes e níveis de proteína bruta em dietas para juvenis de apaiari (Astronotus ocellatus). Acta Scientiarum Animal Science, v.28, n.4, p.477-482, 2006.

FERNANDES, J.B.K.; CARNEIRO, D.J.; SAKOMURA, N.K. Fontes e níveis de proteína bruta em dietas para juvenis de pacu (Piaractus mesopotamicus).

Revista Brasileira de Zootecnia, v.30, n.3, p.617-626, 2001.

GODINHO, H.P. Estratégias reprodutivas de peixes aplicadas à aqüicultura: bases para o desenvolvimento de tecnologias de produção. Revista Brasileira de Reprodução Animal, v.31, n.3, p.351360, 2007.

GOMES, L.C.; GOLOMBIESKI, J.I.; CHIPPARI-GOMES, A.R.; BALDISSEROTTO, B. Biologia do jundiá Rhamdia quelen (Teleostei, Pimelodidae). Ciência Rural, v.30, n.1, p.179-185, 2000.
HAYASHI, C; MEURER, F.; BOSCOLO, W.R.; LACERDA, C.H.F.; KAVATA, L.C.B. Freqüência de arraçoamento para alevinos de lambari do rabo amarelo (Astyanax bimaculatus). Revista Brasileira de Zootecnia, v.33, n.4, p.21-26, 2004.

ITAUSSÚ, D.R.; PEREIRA FILHO, M.; ROUBACH, R.; CRESCÊNCIO, R.; CAVERO, B.A.S.; GANDRA, A.L. Níveis de proteína bruta para juvenis de pirarucu. Pesquisa Agropecuária Brasileira, v.40, n.3, p.255-259, 2005.

IZEL, A.C.U.; PEREIRA-FILHO, M.; MELO, L.A.S.; MACÊDO, J.L.V. Avaliação de níveis de proteicos para a nutrição de juvenis de matrinxã (Brycon cephalus). Acta Amazonica, v.34, n.2, p.179-184, 2004.

KAUSHIK, S.J.; SEILIEZ, I. Protein and amino acid nutrition and metabolism in fish: current knowledge and future needs. Aquaculture Research, v.41, n.3, p.322332, 2010.

LUZ, R.K.; SANTOS, J.C.E. Densidade de estocagem e salinidade de água na larvicultura do pacamã. Pesquisa

Agropecuária Brasileira, v.43, n.7, p.903-909, 2008.

MELO, J.F.B.; LUNDSTEDT, L.M.; MORAES, G.; INOUE, L.A.K.A. Effect of different concentrations of protein on the digestive system of juvenile silver catfish. Arquivos Brasileiros de Medicina Veterinária e Zootecnia, v.64, n.2, p.450-457, 2012.

MEURER, F.; HAYASHI, C.; BOSCOLO, W.R.; SANTOS, L.D.; WOLF, L.; COLPINI, L.M.S. Exigência de proteína digestível para juvenis de tilápia do Nilo (Oreochromis niloticus) em baixa temperatura. Revista Científica de Produção Animal, v.9, n.1, p.53-64, 2007. 
MEURER, F.; OLIVEIRA, S.T.L.; SANTOS, L.D.; OLIVEIRA, J.S.; COLPINI, L.M.S. Níveis de oferta de pós-larvas de tilápia do Nilo para alevinos pacamã (Lophiosilurus alexandri). Revista Brasileira de Ciências Agrárias, v.5, n.1, p.111-116, 2010.

OISHI, C.A.; NWANNA, L.C.; PEREIRA FILHO, M. Optimum dietary protein requirement for Amazonian Tambaqui, Colossoma macropomum Cuvier, 1818, fed fish meal free diets. Acta Amazonica, v.40, n.4, p.757-762, 2010.

PEDREIRA, M.M.; SANTOS, J.C.E.; SAMPAIO, E.V.; PEREIRA, F.N.; SILVA, J.L. Efeito do tamanho da presa e do acréscimo de ração na larvicultura de pacamã. Revista Brasileira de Zootecnia, v.37, p.1144-1150, 2008.

SÁ, M.V.C.; FRACALOSSI, D.M. Exigência protéica e relação energia/proteína para alevinos de piracanjuba (Brycon orbignyanus).

Revista Brasileira de Zootecnia, v.31, n.1, p.1-10, 2002.

SAMPAIO, A.M.B.M.; KUBITZA, F.; CYRINO, J.E.P. Relação energia: proteína do tucunaré. Scientia Agricola, v.57, n.2, p.213-219, 2000.

SEABRA, A.G.L. Manejo alimentar das fases iniciais do pacamã (Lophiosilurus alexandri). 2010. 61f. Dissertação (Mestrado em Ciência Animal) - Universidade Federal do Vale do São Francisco, Petrolina.

SILVA, D.J.; QUEIROZ, A.C. Análise de alimentos: métodos químicos e biológicos. 3.ed. Viçosa: Universidade Federal de Viçosa, 2006. 235p.
SOARES, E.C.; PEREIRA FILHO, M.; ROUBACH, R.; SILVA, R.C.S. Condicionamento alimentar no desempenho zootécnico do tucunaré. Revista Brasileira de Engenharia de Pesca, v.2, p.35-48, 2007.

TEIXEIRA, B.; MACHADO, C.C.; FRACALOSSI, D.M. Exigência proteica em dietas para alevinos do dourado (Salminus brasiliensis). Acta Scientiarum. Animal Sciences, v.32, n.1, p.33-38, 2010.

TENÓRIO, R.A.; SANTOS, A.J.G.; LOPES, J.P.; NOGUEIRA, E.M.S. Crescimento do niquim (Lophiosilurus alexandri, Steindachner 1876), em diferentes condições de luminosidade e tipos de alimento. Acta Scientiarum.

Biological Science, v.28, n.4, p.305-309, 2006.

TIBBETTS, S.M.; LALL, S.P.; ANDERSON, D.M. Dietary protein requirement of juvenile American eel (Anguilla rostrata) fed pratical diets. Aquaculture, v.186, n.1-2, p.145-155, 2000 .

UNIVERSIDADE FEDERAL DE VIÇOSA - UFV. SAEG Sistema para análises estatísticas e genéticas. Versão 7.1. Viçosa, MG, 1997. 150p.

VÁSQUEZ-TORRES, W.; PEREIRA FILHO, M.; ARIAS-CASTELLANOS, J.A. Optimum dietary crude protein requeriment for juvenile cachama Piaractus brachypomus. Ciência Rural, v.41, n.12, p.2138-2189, 2011.

VERAS, G.C.; SALARO, A.L.; ZUANON, J.A.S.; CARNEIRO, A.P.S.; CAMPELO, D.A.V.; MURGAS, L.D.S. Growth performance and body composition of giant trahira fingerlings fed diets with different protein and energy levels. Pesquisa Agropecuária

Brasileira, v.45, n.9, p.1021-1027, 2010. 
Rev. Bras. Saúde Prod. Anim., Salvador, v.14, n.2, p.362-370 abr./jun., 2013 http://www.rbspa.ufba.br ISSN 15199940

VIDAL JÚNIOR, M.V.; DONZELE, J.L.; CAMARGO, A.C.S.; ANDRADE, D.R.; SANTOS, L.C. Níveis de proteína bruta para tambaqui (Colossoma macropomun), na fase de 30 a 250

gramas. 1. Desempenho dos tambaquis. Revista Brasileira de Zootecnia, v.27, n.3, p.421-426, 1998.

Data de recebimento: 09/01/2013

Data de aprovação: 04/06/2013 